\title{
Blood urea nitrogen/creatinine index is a predictor of prerenal damage in preeclampsia
}

\author{
Hidajet Paçarizi ${ }^{1 *}$, Luljeta Begolli1 ${ }^{1}$, Shefqet Lulaj $^{2}$, Zana Gafurri ${ }^{1}$
}

${ }^{1}$ Department of Biochemistry, Faculty of Medicine, University of Prishtina, Mother Teresa n.n, 10000 Prishtina, Kosovo

${ }^{2}$ Department of Obstetrics and Gynecology, University Clinical Centre of Kosovo, Mother Teresa n.n, 10000 Prishtina, Kosovo

\begin{abstract}
Introduction: Preeclampsia is a disease whose etiology is not very clearly explained. The aim of this study was to investigate the importance of blood urea nitrogen (BUN)/creatinine ratio in diagnosing preeclampsia and evaluating prognosis.

Methods: The patients in this research were examined and diagnosed in the Department of Obstetrics and Gynecology, University Clinical Centre of Kosovo. Control group included 25 pregnant women with a normal blood pressure and with a gestational age of more than 20 weeks, whereas the investigation group included 25 women diagnosed with preeclampsia. The patients were not administered therapy four days before the examination. For the determination of biochemical parameters we used end point bichromatic enzymatic rate and enzymatic conductivity rate.

Results: BUN/Creatinine index in the preeclamptic group was $19 \pm 7.7$, uric acid $280 \pm 70 \mu \mathrm{mol} / \mathrm{L}$, lactate dehydrogenase $198 \pm 63 \mathrm{U} / \mathrm{L}$, while the number of platelets was $195 \pm 5061 \times 10^{\circ} / \mathrm{L}$. In control group BUN/Creatinine index was $12 \pm 3$, lactate dehydrogenase was $165 \pm 57 \mathrm{U} / \mathrm{L}$, uric acid $197 \pm 79 \mu \mathrm{mol} / \mathrm{La}$ and the platelet number was $243 \pm 61 \times 10^{9} / \mathrm{L}$. Albumin/Globulin index in the preeclamptic group was $0.8 \pm 0.12$, whereas in the control group it was $0.9 \pm 0.16$.

Conclusions: BUN/Creatinine ratio in pregnant women with preeclampsia was significantly increased $(\mathrm{t}=-$ 4.14; $p=0.00013$ ) in comparison to the control group. It indicates the prerenal source of azotemia. This index can be important for the evaluation of preeclampsia severity.

(C) 2012 All rights reserved
\end{abstract}

Keywords: preeclampsia, BUN/Creatinine ratio, Albumin/Globulin ratio.

\section{Introduction}

Preeclampsia is a specific state of pregnant women which involves an increase of arterial blood pressure, accompanied by proteinuria, oedema or both. Eclampsia, on the other hand, is defined as a state with convulsion, coma or both in patients with preeclampsia signs (1-6). The incidence of preeclampsia is $5-7 \%$ in all pregnancies (1-6). One of the causes of preeclampsia can be considered the disbalance between prostacyclin (prostaglandin I2) and thromboxane A2, an active metabolite of arachidonic acid $(1,5,6)$. This disbalance causes vasospasm, a central change in preeclampsia (1). Presence of brain edema at MR imaging in

\footnotetext{
* Corresponding author: Hidajet Paçarizi,

Nënë Tereza 48A/1 Prishtinë, Kosovo

Phone: +386 49137239 ,

e-mail: hidajetp@hotmail.com
}

Submitted 29. February 2012 / Accepted 19. April 2012 patients who were presented with preeclampsiaeclampsia and neurologic symptoms is associated with abnormal red blood cell morphology and elevated LDH levels. These findings indicate microangiopathic hemolysis, which suggests endothelial damage, after 20th week of pregnancy (7). A number of biochemical and haematological parameters change in preeclampsia in comparison to the normal pregnancy $(3,8-10)$. Therefore, laboratory evaluation of women who develop hypertension after midpregnancy is conducted and it usually includes: haemoglobin and haematocrit determination, blood smear, platelet count, urinalysis as well as the determination of serum oxaloacetic transaminase, lactic acid dehydrogenase, serum albumin, uric acid and creatinine (7, 9-13). The literature suggests that no single marker is currently adequate to predict the development of preeclampsia and that a combination of indices would be most effective (14-16). Increased plasma 
urea with normal creatinine concentrations giving rise to high ratios may be seen with any of the prerenal states (17). However, blood urea nitrogen/ creatinine has been used as a crude discriminator between prerenal and postrenal azotemia (17-18). The purpose of this research was to investigate that BUN/Creatinine index is a preeclampsia predictor together with the other diagnostic parameters which would help diagnosing, treatment and prognostic evaluation of preeclamptic women.

\section{Methods}

\section{Study Subjects}

We have studied 25 pregnant women of the preeclamptic group and 25 patients of control group. Control group has resulted with no symptoms related to preeclampsia while in the preeclamptic group there were pregnant women with preeclampsia signs, hypertension, oedema and proteinuria. The patients were selected in the Obstetrical and Gynaecological Clinics of University Clinical Centre of Kosovo, whereas the sample analysis took place in the Department of Biochemistry of the Faculty of Medicine, University of Prishtina, during 2011. The women of the preeclamptic group were in the gestational age of 20 weeks, with an arterial pressure of over $140 \mathrm{~mm} \mathrm{Hg}$ for the systolic and over $90 \mathrm{~mm} \mathrm{Hg}$ for the diastolic. Hypertension appeared during pregnancy. Proteins in urine were over $0.5 \mathrm{~g} / \mathrm{L}$. All the patients had oedema of lower extremities while $80 \%$ had oedema of upper extremities and face as well. On the other hand, control group included pregnant women with a gestational age of over 20 weeks, normal arterial pressure $(<135 / 85 \mathrm{mmHg})$ and a lack of symptoms as those described in the preeclamptic group.

\section{Detailed analysis}

The blood was taken from patients with vacutainer tubes (SARSTEDT) containing the anticoagulant lithium heparin and in tubes without anticoagulants. Platelets were determined in the automatic reader (Medonic 630, Sweden). Biochemical parameters were determined in the biochemical analyzer Synchron CX7 of Beckman Coulter Company, USA. The used reagents were of Beckman Instrumental, Inc. Galway. Ireland. Urea nitrogen concentration was determined by an enzymatic conductivity rate method; creatinine by means of the Jaffe rate method; Lactate dehydrogenase activity was measured by the enzymatic rate method. Uric acid concentration was measured by a timed-endpoint method with the enzyme uricase. Proteins in serum were measured by a timed-endpoint biuret method and albumins were determined with brome cresol purple (BCP), a timed endpoint method as well (26). We have determined proteins in urine with the end point method with pyrogallol red, a reagent of Cromatest- Linear Chemicals Company, Spain.

\section{Statistical analysis}

The statistics were made with the Vassar-Stats system. T-test was conducted and the average, correlation $(r)$ and standard deviation were counted. These are shown in the tabular presentation. With the $\mathrm{t}$ test we have compared control and preeclamptic group by including the pregnancy age, gestation age, systolic and diastolic arterial pressure as well as biochemical parameters such as urea, creatinine, proteins, albumins, $\mathrm{LDH}$, uric acid, Bun/Creatinine index, A/G index and platelets. The average and standard deviations were calculated for all the parameters and indexes. The correlation between Bun/Creatinine and Albumin/Globulin, Bun/Creatinine and Uric acid, Bun/Creatinine and LDH was calculated in control group. The same correlations were calculated for the pathologic group. The differences in which the $p$ value was less than 0.05 $(p<0.05)$ were considered statistically significant.

\section{Results}

The patients of control group $(n=25)$ were $28 \pm 6$ years old, while the preeclamptic group $(n=25)$ $30 \pm 6$. The age of pregnancy for both groups was $>20$ weeks with an average of 33 weeks gestation. The preeclamptic group's diastolic arterial blood pressure was (DATP) $115 \pm 14 \mathrm{mmHg}$, while that of control group was $75 \pm 5 \mathrm{~mm} \mathrm{Hg}$. Systolic arterial blood pressure was $115 \pm 5 \mathrm{~mm} \mathrm{Hg}$ for the control group, while for the group with preeclampsia $175 \pm 13 \mathrm{~mm}$ Hg. Parameters like urea, creatinine, protein, albumin, uric acid, LDH (lactate dehydrogenase), the number of platelets, blood urea nitrogen/creatinine index and albumin/globulin index, have been presented in Table 1. In table 3 we have presented the difference between Blood urea ni- 
TABLE 1. Some characteristics and parameters in the control and preeclamptic group

\begin{tabular}{|c|c|c|c|c|}
\hline & CG & $P G$ & $T$ & $p$ \\
\hline $\mathrm{N}$ & 2 & & & \\
\hline Year & $28 \pm 6$ & $30 \pm 6$ & -0.72 & 0.47 \\
\hline $\begin{array}{l}\text { Gestational } \\
\text { age, wk }\end{array}$ & $33 \pm 4$ & $33 \pm 4$ & 0.09 & 0.928 \\
\hline SATP (mmHG) & $115 \pm 5$ & $175 \pm 13$ & -20.77 & $<0.0001$ \\
\hline DATP (mmHg) & $75 \pm 5$ & $115 \pm 14$ & -13.49 & $<0.0001$ \\
\hline Urea (mmol/L) & $2.46 \pm 0.8$ & $4.6 \pm 1.7$ & -4.92 & $<0.0001$ \\
\hline $\begin{array}{l}\text { Creatinine } \\
(\mu \mathrm{mol} / \mathrm{L})\end{array}$ & $53 \pm 10$ & $64 \pm 22$ & -1.62 & 0.11 \\
\hline $\begin{array}{l}\text { Total protein } \\
(\mathrm{g} / \mathrm{L})\end{array}$ & $65 \pm 4.6$ & $59.4 \pm 5.8$ & 1.69 & 0.09 \\
\hline Albumin (g/L) & $31.3 \pm 2.8$ & $27 \pm 3,6$ & 2.2 & 0.03 \\
\hline URIC ( $\mu \mathrm{mo} / \mathrm{L})$ & $197 \pm 79$ & $280 \pm 70$ & -3.39 & 0.0013 \\
\hline LDH (U/L) & $165 \pm 57$ & $198 \pm 63$ & -1.73 & 0.093 \\
\hline $\begin{array}{l}\text { Blood urea } \\
\text { nitrogen/creati- } \\
\text { nine index }\end{array}$ & $12 \pm 3$ & $19 \pm 7.7$ & -3.92 & 0.00027 \\
\hline$A / G$ & $0.9 \pm 0.16$ & $0.8 \pm 0.12$ & 1.28 & 0.2 \\
\hline $\begin{array}{l}\text { Protein } \\
\text { (in urine) }\end{array}$ & $0.13 \pm 0.1$ & $1.41 \pm 0.9$ & -6.81 & $<0.0001$ \\
\hline Platelet x109/L & $243 \pm 61$ & $195 \pm 50$ & +2.06 & $<0.045$ \\
\hline
\end{tabular}

trogen/Creatinine ratio in the group with a normal blood pressure and the preeclampsia group, as well as the $\mathrm{A} / \mathrm{G}$ ratio between the two groups with t-test.

\section{Discussion}

Creatinine, urea and uric acid are non-protein nitrogenous metabolites that are cleared from the body by the kidney following glomerular filtration. Measurements of plasma or serum concentration of these metabolites are commonly used as indicators of kidney function and other conditions $(14,17)$. Therefore, their determination in serum during pregnancy is of a major importance to diagnose kidney function especially at women with preeclampsia signs. This would be used to evaluate kidney function as well as the possibility of a secondary source of urea or of the nitrogen part of urea increase (Blood urea nitrogen ) in plasma. The significant difference between arterial systolic and diastolic blood pressure between control group and the pregnant women with preeclampsia signs is clearly shown $(\mathrm{t}=-20$ and for diastolic $\mathrm{t}=-13$, Table 2). The difference occurs in BUN/Creatinine ratio,
TABLE 2. The correlation between Blood urea nitrogen/Creatinine ratio and parameters such as uric acid, LDH and A/G ratio in both groups has been summarized.

\begin{tabular}{lccc}
\hline \multicolumn{1}{c}{ Ratio } & Number & $\mathrm{r}$ & $\mathrm{p}$ \\
\hline $\begin{array}{l}\text { Bun/Creatinine -Albumin/ } \\
\text { Globulin(CG) }\end{array}$ & 13 & 0.035 & 0.87 \\
\hline $\begin{array}{l}\text { Bun/Creatinine-Albumin/ } \\
\text { Globulin(PG) }\end{array}$ & 22 & 0.420 & 0.04 \\
\hline Bun/Creatinine-uric(CG) & 12 & -0.162 & 0.59 \\
\hline Bun/Creatinine -uric(PG) & 21 & 0.294 & 0.18 \\
\hline Bun/Creatinine -LDH(CG) & 12 & -0.021 & 0.95 \\
\hline B/C-LDH(PG) & 21 & -0.042 & 0.86 \\
\hline
\end{tabular}

which is characterized with an increase of this ratio in the pathologic group (BUN/Creatine ratio $=19 \pm 8)$ in comparison to control group BUN/ Creatinine $=12 \pm 3(\mathrm{t}=-3.92 ; \mathrm{p}=0.00027$, Table 2). This can be explained with the occurrence of microangiopathic haemolysis, which is related to the injury of endothelium in the group with preeclampsia changes (Fig. 1, 1,4,8,20-24,27-28). As a consequence, urea synthesis in liver would be increased as well as the incapability of kidneys to excrete urea from blood with such a high concentration. This way we would have a more complete data. There is no significant difference between the A/G ratio of control group and the preeclamptic one, although a tendency for a decrease is seen in the group with preeclampsia (Table 3). The difference between albumins of CG and those of PG is statistically significant $(\mathrm{p}=0.03)$. This is because the protein removal in urine, in the group of preeclamptic women, is increased with an average amount of $1.41 \pm 0.9 \mathrm{~g} / \mathrm{L}$ (Table 1 ) which brings to the decrease of albumins in serum with an average value of $27 \pm 3.6 \mathrm{~g} / \mathrm{L}(25)$. The level of urea in serum at the patients of preeclamptic group is significant-

TABLE 3. T-test Blood urea nitrogen/Creatinine and $A / G$ index between control and preeclamptic group

\begin{tabular}{lcccc}
\hline & $\begin{array}{c}\text { Blood urea } \\
\text { nitrogen/Cre- } \\
\text { atinine-CG }\end{array}$ & $\begin{array}{c}\text { Blood urea } \\
\text { nitrogen/Cre- } \\
\text { atinine -PG }\end{array}$ & A/G-CG & A/G-PG \\
\hline $\mathrm{N}$ & 25 & $19 \pm 7.7$ & $0.9 \pm 0.16$ & $0.8 \pm 0.12$ \\
\hline Mean & $12 \pm 3$ & -3.92 & 1.28 \\
\hline $\mathrm{T}$ & 0.00027 & 0.2 \\
$\mathrm{P}$ & & & 25 \\
\hline
\end{tabular}

*Mean of two measurements of calibrators as sample. 
ly increased $\mathrm{p}<0,0001$, in comparison to control group(Table 1). The comparison between creatinine in the serum of control group and of pregnant women with preeclampsia is also shown there and in this case an evident increase of creatinine at the preeclamptic group is obvious $(\mathrm{p}=0,11)$. The difference between the increase of blood urea nitrogen and creatinine in blood, shows a secondary source of urea related to the increase of its synthesis. As a consequence of the increase of BUN and the decrease of albumins, there exists a regressive correlation between BUN/Creatinine and A/G index at the preecplamptic group (Table 2). Also, in the preeclamptic group there was a significant decrease of platelets (Table 1) as a result of the increased rate of coagulability in this group $(8,21-22,25)$.

\section{Conclusion}

In this research, blood urea nitrogen/creatinine index was significantly increased in pregnant women with preeclampsia in comparison to the group of pregnant women with normal blood pressure. It indicates the prerenal source of urea. This index can be important to estimate the severity of preeclampsia.

\section{Acknowledgments}

We thank the personnel of the Institute of Biochemistry-University of Prishtina for their support during this study.

\section{Competing interests}

This study was supported by the University Clinical Center, Department of Biochemistry and Department of Obstetrics and Gynecology in Prishtina.

\section{References}

(1) Smith MA. Preeclampsia. Prim Care. 1993; 20(3):655-664.

(2) Cooray SD, Edmonds SM, Tong S, Samarasekera SP, Whitehead CL. Characterization of symptoms immediately preceding eclampsia. Obstet Gynecol. 2011;118(5): 995-999.

(3) Lydakis C, Beevers M, Beevers DG, Lip GY. The prevalence of preeclampsia and obstetric outcome in pregnancies of normotensive and hypertensive women a hospital specialist clinic. Int J Clin Pract. 2001; 55 (6):361-367.

(4) Sibai BM. Diagnosis, prevention, and management of eclampsia. Obstet Gynecol. 2005;105(2):402-410

(5) Vigil-De GP. Maternal deaths due to eclampsia and HELLP syndrome. Int J Gynaecol Obstet. 2009; 104(2):90-94

(6) Hutcheon JA, Lisonkova S, Joseph KJ. Epidemiology of pre-eclampsia and the other hypertensive disorders of pregnancy. Best Pract Res Clin Obstet Gynaecol. 2011; 25(4):391-403.

(7) Schwartz RB, Feske SK, Polak JF, DeGirolami U, Iaia A, Beckner KM, et al. Preeclampsia-Eclampsia: Clinical and Neuroradiographic Correlates and Insights into the Pathogenesis of Hypertensive Encephalopathy. Radiology. 2000; 217:371-376
(8) Boehm DF, Salat A, Vogl SE, Murabito $M$, Felfernig $M$, Schmidt D, et al. Early detection eclampsia by determination of platelet aggregability. Thromb Res. 2000; 98(2):139146.

(9) Leeman L. Hypertensive Disorders of Pregnancy. Am Fam Physician. 2008; 78(1):93-100.

(10) Lurie S, Mamet Y. Red blood cell survial and kinetics during pregnancy. Eur J Obstet Gynecol Reprod Biol. 2000; 93(2) :229-231.

(11) Gifford R, August P, Chesley L. National High Pressure Education Program Working group. Am J Obstet Gynecol.1990; 163:1689-1712.

(12) Felfernig BD, Salat A, Vogl SE, Murabito M, Felfernig M, Schmidt D. et al. Early detection of preeclampsia by determination of platelet aggegability. Thromb Res. 2000; 15; 98(2): 139-146

(13) Baweja S, Kent A, Masterson R, Roberts S, McMahon L. Prediction of pre-eclampsia in early pregnancy by estimating the spot urinary albumin: creatinine ratio using highperformance liquid chromatography. BJOG. 2011;118(9):1126-1132.

(14) Meads CA, Cnossen JS, Meher S, Juarez GA, Riet G, Duley L, et al. Methods of prediction and prevention of pre-eclampsia: systematic reviews of accuracy and effective- ness literature with economic modelling. Health Technol Assess. 2008;12(6): 1-270

(15) Dadelszen P, Payne B, Li J, Ansermino JM, Broughton PF, Côté AM, et al. Prediction of adverse maternal outcomes in pre-eclampsia: development and validation of the fullPIERS model. Lancet. 2011; 377(9761):219-227.

(16) Chappell LC, Seed PT, Briley A, Kelly SRN, Frank J, Hunt BJ, et al. A longitudinal study of biochemical variables in women at risk of preeclampsia. Am J Obstet Gynecol. 2002; (187):127-136.

(17) Lumb E, Price LCJ, Hsich TT, Chiu TH, Chen KC, Lo LM,et al. Creatinine, urea, and uric acid, In: Burtis C, Asswood E, Bruns D. Tietz Fundamentals of Clinical Chemistry, 6 th ed, Saunders, Elsevier. 2008:3 63372.

(18) Jeyabalan A, Conrad KP. Renal function during normal pregnancy and preeclampsia. Frontiers in Bioscience. 2007; 12 (1): 2425-2437.

(19) Sirpa T, Eero R, Pirjo H, Esko V, Raimo V. MATERNAL Preeclampsia Predicts Elevated Blood Pressure in 12-Year-Old Children: Evaluation by Ambulatory Blood Pressure Monitoring. Pediatric Research. 2006; 59:320-324. 
(20) Idogun ES, Imarengiaye CO, Momoh SM. Extracellular Calcium and Magnesium in Preeclampsia and Eclampsia. African Journal of Reproductive Health. 2007; 11 (2): 89-94.

(21) Eddib A, Yeh J. Prevention of Preeclampsia: Is it Still a Disappointment? Clinical Medicine. Women's Health. 2009;2: 9-15

(22) Hladunewich M, Karumanchi SA, Lafayette R. Pathophysiology of the Clinical Manifestations of Preeclampsia. Clin J Am Soc Nephrol.
2007; 2: 543-549.

(23) Sibai BM, Barton JR. Expectant management of severe preeclampsia remote from term: patient selection, treatment, and delivery indications. Am J Obstet Gynecol. 2007;196(6):514-523.

(24) Zeeman GG, Hatab MR, Twickler DM. Increased cerebral blood flow in preeclampsia with magnetic resonance imaging. Am J Obstet Gynecol. 2004; 191(4): 1425-1429

(25) Paçarizi H. Correlation between magnesium, calcium and pre- eclampsia. University of Prishtina. 2007(dissertation)

(26) Chemistry Information Manual 1-2, Beckman Coulter Company 1998.

(27) Myatt L, Webster RP. "Is vascular biology in preeclampsia better?" Journal of Thrombosis and Haemostasis. 2009; 7:375-384.

(28) Stillman IE, Karumanchi SA. "The glomerular injury of preeclampsia," Journal of the American Society of Nephrology. 2007; 18 (8): 22812284. 